a common denominator for these needs. If the criticism of traditional cataloging degenerates into rugged individualism, we are bound to retrogress; if it develops into a planned economy of cataloging, we shall be on the road to the future. It is suggested that we make the code a guidepost to that road.

By MAURICE F. TAUBER

\title{
Subject Cataloging and Classification Approaching the Crossroads
}

\section{Mr. Tauber is chief, catalog department, University of Chicago Libraries.}

Despite the criticisms that may justifiably be directed at descriptive cataloging, particularly its expense and its detailed, bibliographical nature, it generally has been found that the procedures in this sphere of cataloging in university libraries are fairly well standardized on the basis of either the A.L.A. or the L.C. rules. Standardization is less prevalent in the areas of subject headings and classification, although standard lists of headings and systems of arrangement are commonly used. It is not surprising, therefore, that there should be some suggestions for reforms in subject heading and a few in classification policies. This paper will deal first of all with some of the reforms that have been proposed. It will also discuss the extent of our knowledge of current subject-heading work and classification practices and of their effects upon use of library materials. Finally, it will record briefly some data concerning centralized and cooperative cataloging and classification, aspects which I assume will be treated by Mr. Haykin.
The participant observer of library use generally is in a better position than the armchair philosopher to discuss these matters in full detail. The latter can raise questions and make suggestions for changes, but unless careful analyses and accurate tests are made, many of our statements regarding subject headings and classifications remain assumptions. Actually there are few data derived from systematic research, as Randall recently pointed out. ${ }^{1}$ Since this lack of data makes complete documentation difficult, the following résumé should be regarded as being primarily exploratory. As yet, there are no clear signposts which indicate the procedures which will accomplish the things administrators have come to regard as important in the technical processes-economical practices which serve the users and enable the staff to aid the users.

\section{Subject Headings}

Under the rubric of subject headings, it may be said that we think we know why we do certain things, but are pretty

\footnotetext{
1 Randall, William M. "The Technical Processes and Library Service," in his The Acquisition and Cataloging of Books. Chicago, University of Chicago Press, I 940, p. I-29.
} 
much in the dark regarding the results of our practices. The problem of subject headings is a difficult one in every respect, primarily because, as Osborn recently pointed out, ${ }^{2}$ words are not only variously interpreted by users but also change in meaning; because subject heading work is an art rather than a science and depends upon intelligence rather than rules; and because there has been no clear differentiation of the subject needs of patrons in different types of libraries. It is unlikely that we can surmount immediately and completely the difficulties arising from wide connotation of words. However, it should not be impossible with proper instruction and adequate compensation to secure intelligent cataloging personnel with the subject backgrounds and experience that are necessary for discriminatory subject heading work in academic libraries, once we know what approach faculty members and students make to subject heading cards and what uses they make of them. Finally, so far as university libraries are concerned, it may be assumed that they are less likely to attract the heterogeneous clientele found in some other types of libraries.

Even with a qualified personnel will we produce subject headings which, barring such obstacles as misinterpretation, ambiguity, technicality, and obsolescence of words, serve the needs of an academic clientele? This is a crucial question which, without evidence from objective studies, can be answered only in speculative terms. On the basis of knowledge accumulated from the experiences of reference and circulation librarians, it becomes apparent that the procedures for assigning subject headings as set down by Cutter

${ }^{2}$ Osborn, Andrew D. "The Crisis in Cataloging." Library Quarterly I I:409-10, Oct. I94I. in 1904 are as valid today as they were two decades ago. Therefore, it is interesting to note that suggested changes in procedures which concern such matters as using specific subjects and making adequate cross references have been relatively few. Instead, the critics have been concerned with such aspects as (I) the nature of subject headings themselves, and (2) the number of subject headings. Both of these are considered in relation to the approach of the users.

\section{Nature of Subject Headings}

The lack of clarity and the technical and obsolete nature of subject headings have been singled out by critics for consideration. As was noted above, as long as words are used there is likely to be some disagreement in the choice of them. Standard rules and standard lists, such as those of the Library of Congress, can guide the cataloger, but do not remove the difficulties met by users. Connotation of words depends upon such factors as background and training of the individual students, faculty members, and research workers, as well as upon their approach to specific problems. Definitions of terms, with sufficient cross references, however, may reduce considerably the differences which arise from misinterpretation. Instruction in library usage in relation to course work may also serve to minimize difficulties. No such meeting of minds can be easily achieved in regard to technical aspects of subject headings. Butler has called attention to "the futility of subject catalogs as reference tools in any humanistic area,"3 while Shaw has offered limited evidence which suggests at least that "scientists and technologists do not

3 Butler, Pierce. "The Research Worker's Approach to Books-the Humanist," in Randall, $o p$. cit., p. 282. 
use library subject catalogs in their specialties." 4 Actual, replacement of outmoded subject headings by new terminology is primarily an administrative problem and is carried on only to a small extent in large catalogs because of the expense involved.

\section{Number of Subject Headings}

Proposals for catalog reform invariably arise from conditions developing from the size of the catalogs. The potentialities of growth in catalogs in the future have been estimated in astronomical figures by Rider, who, correctly or not, bases his predictions primarily upon past happenings. ${ }^{5}$ At the present time, the average library user, confronted with a tray or more of cards on a single subject is said to be confused and bewildered. No evidence regarding the prevalence or intensity of this bewilderment is available. But proposals for eliminating alleged difficulties in using the catalog are plentiful. These include abolishing the catalog, reducing it, or splitting it in various ways. Microphotography and book catalogs have been suggested as substitutes for the present dictionary card catalog. In a recent paper by Pettee, ${ }^{6}$ five suggestions for reducing subject entries in catalogs were offered: (I) Eliminating all general headings where a specific heading covers the subject, (2) Selecting the main topic and discarding other closely related headings for overlapping topics, (3) Using cross references to cover double headings, i.e., headings covering identical material in

4haw, Ralph R. “The Research Worker's Approach to Books-the Scientist," in Randall, op. cit., p. 300 Rider, Fremont. "Alternatives for the Present Dictionary Catalog," in Randall, op. cit., p. I 35-62.

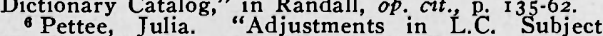
Headings for Research Libraries." "Paper given at the meeting of the New York Regional Catalog Group, Feb. I 4, r94I. Unpublished ms. (Used with permission.)

MARCH, 1942 which phraseology is reversed, (4) Omitting certain types of subject headings, and (5) Eliminating analytics for collected essays, including serials and nonmonographic sets. There seems to be no question that in these five areas there are possibilities for substantially reducing the size of the catalog without seriously decreasing its service to users.

Hitchcock $^{7}$ has recorded the extent to which eighty-nine university libraries omit subject cards for certain items and has given us some idea of how libraries are attempting to solve the problems of size and cost. She found that for four fifths of the ninety types of materials for which subject headings could be omitted, a significant number of libraries do omit them, even though they do not all select the same types of material. In more than half of the libraries there is common action regarding the omission of subject cards for fourteen main types of materials. These include material with an indefinable subject, material in departmental libraries off campus, pamphlet collections, government document collections, and other materials represented in the catalog under subject by proxy. The general principle of assigning a subject "to every book with a definable subject" is now qualified by such considerations as use, economy, and uniqueness. To the administrator, the problem is to decide whether or not special groups of persons, such as those who use departmental libraries, should be served by the main catalog or by departmental subject catalogs. Hitchcock concludes that small catalogs are more valuable if they are made with the purpose of serving defi-

THitchcock, Jennette E. "The Coverage of Materials under the Subject Entries of the Dictionary Catalog in American University Libraries." M.A. thesis, University of Chicago, 1939. Also issued in abstract form in Library Quarterly 10:69-94, Jan. I 940. 
nite readers. There seems to be little doubt that the divided catalog is an attempt to get at different types of catalog users in the general library. Similarly, the introduction of "self-cataloging" methods indicates an attempt to meet the approach of particular types of library patrons.

\section{Period Cataloging}

Another suggestion advanced for overcoming the difficulties of both obsolescence and size is to develop a procedure which might be termed "period cataloging." This might take one of two forms: (I) Placing subject entries for only the latest items in the public catalog and using cross references to the shelflist for earlier works, or (2) Developing a system of duplicate catalogs, one of which is to contain entries for current works, such as those of the last five or ten years. The disadvantages of both of these plans are obvious but unless we have some contrary evidence possibly based on controlled experiments, either plan may have considerable usefulness.

The suggestion has also been made to split the catalog. Papers on this procedure have been appearing with increasing frequency in recent literature. Discussions by Wood, Dean, Lubetzky, and Wright in the Catalogers' and Classifiers' Yearbook for 1939 consider some of the problems which arise from the divided catalog. Whether or not the divided cata$\log$ is the solution to the difficulties of size and complexity remains to be seen. It may be said here as elsewhere that at present we have little idence that the split catalog is the proper alternative in every library. Rider suggests that it may be the beginning of a trend, the first step back to the classed subject catalog, once abandoned for the dictionary catalog. In an article in the first issue of College and Research Libraries, Leupp prophesied that the acceptance of the classed catalog is likely to become more common in large libraries. ${ }^{8}$ But this also remains to be seen. There should be careful studies of use in those libraries in which catalogs have been divided. It is unfortunate that systematic studies of the use of the catalog were generally not made in the libraries prior to the division of entries. Changes have been made too often on the basis of guesswork.

Possibilities for reducing entries in card catalogs are also present in the suggestion to prepare more subject bibliographies and indexes. This is a fertile field that has been given much lip service but not the attention that it deserves. Would it be more economical, for example, to produce cooperatively printed subject analytical indexes of volumes now analyzed separately in card catalogs by many large libraries?

Whether or not storage libraries of old and little-used materials will have some effect upon the present practices of subject cataloging is also a problematical matter. It is possible that the storage of books may be accompanied by the storage of cards which have been reproduced on film. Simple types of cataloging and classification may well be used for materials placed in storage.

\section{Approach of the Users}

There is a growing interest in the approach of users to the card catalog. Some individuals who have not thought through all problems involved are willing to abolish the catalog without providing a satisfactory substitute for it. But many librarians, noncatalogers as well as cata-

\footnotetext{
8 Leupp, Harold L. "Probable Trends in University Libraries." College and Research Libraries $1: 60$, Dec. 1939.
} 
logers, hold the conservative view that is presented by McColvin, the English librarian, who notes that the catalog cannot be a scientific tool with its essential cross references, analytical entries, and other complications of modern practice and at the same time be "understandable by the veriest child." Although written from a public library viewpoint, the statement seems to apply as well to university libraries. But McColvin avoids the basic question of the need of the complex tool.

Mention may be made at this point of two studies which provide some facts regarding the usefulness of subject catalogs and the uses made of them. Kelley, in her study of the subject approach to books, concluded that "of all the material on a subject in a well-made dictionary catalog, one third is shelved under the subject's specific class number, one third appears in the form of analytical entries shelved in the main series, and one third is shelved elsewhere." 10 Thus it is concluded the subject catalog supplements classification, and its flexibility makes it a better medium than classification for indicating the subject resources of the library. ${ }^{11}$

Kelley's findings indicate the quantity of material one might expect to find through the subject catalog. They do not indicate what actual use is made of subject entries. A preliminary study of the use of the card catalog is reported by Miller in an article to be published shortly in the Library Quarterly. ${ }^{12}$ Miller found that of the 870 patrons interviewed in the libraries of the universities of Colorado, Nebraska, and Wisconsin, 52 per cent used the catalog to locate books, $4 \mathrm{I}$ per cent to

${ }^{9}$ McColvin, L. R. Libraries and the Public. London, Allen \& Unwin, 1937, p. 50.

${ }^{10}$ Kelley, Grace O. The Class
New York, Wilson, 1937, p. I 25.
11 Ibid.

${ }_{12}^{11}$ I Miller, Robert A. "On the Use of the Catalog." Unpublished ms. (Used with permission.) select books on a given subject, and 7 per cent for bibliographical information. Undergraduate students at the three institutions "used the catalog more as an aid in selecting books on a given subject than did the graduate students." The latter used the catalog mostly for locating books. Quantitative evidence leads Miller to suggest that subject headings might be developed for undergraduate needs and vocabulary rather than for graduate demands. Local conditions, of course, need to be considered, for instructional and research programs directly affect the use of library materials. The real reason for the absence of use by graduate students and specialists may well lie in the fact that catalogs are infrequently made to fulfill special needs.

\section{Classification}

During the last two decades there has been a gradual shift of interest away from classification as a topic of discussion at conferences and in the professional literature. This has been true largely because most of the major university libraries needing reclassification have been reorganized by the L.C. schedules, and librarians of other institutions have become convinced that the perfect classification is a will-o'-the-wisp and are unwilling to incur the expense of reclassification. Most of the reasons for reclassification have been based on either or both of two assumptions: (I) That the use of the new classification achieves a grouping of the books in the collection that is of greater educational significance and shows to the users the currently accepted relationships among the branches of knowledge more effectively than did the system being replaced, and (2) That the adoption of a new classification will reduce the costs of tech- 
nical processes. The specific reasons advanced by librarians for reclassification by the Library of Congress schedules were listed in some detail in a paper at the Graduate Library School Institute last year, ${ }^{13}$ and there would be no point in recording them again here. It may be repeated, however, that the absence of a clear understanding of the realities of book classification has resulted in rationalizations on the part of some librarians who attempt to justify reclassification.

\section{Proposed Reforms in Classification}

The proposed reforms in classification, in addition to outright reclassification, have been relatively few. Probably the most interesting proposal was made by Lund and Taube. ${ }^{14}$ Their scheme of period classification, designed to eliminate reclassification, has been criticized by $\mathrm{Bliss}$ and others as being unsound in practice. Studies of the use of library materials from the standpoint of time periods are fundamental to reach decisions on the question of whether or not reclassification would be advantageous or necessary in a particular library. A by-product of such studies might indicate how practicable a period classification such as suggested by Lund and Taube would be.

Rider's proposal for reclassifying without actually changing the books should be noted. According to this procedure, shifts in emphasis resulting from geographicalpolitical-military changes or from new discoveries in research which affect groupings of books are to be readjusted by the transfer of subject cards bodily from one place

13 Tauber, Maurice F. "Reclassification and Recataloging, of Materials in College and University Libraries," in Randall, op. cit., p. 194-202.

14 Lund, John J. and Taube, Mortimer. "A NonExpansive Classification: an Introduction to Period Classification." Library Quarterly 7:373-94, July 1937; see also comments by H. E. Bliss, Library
Quarterly $8: 120 \cdot 24$, Jan. 1938, and by W. S. Merrill, Quarterly $8: 1$
ibid., $124-26$. to another in a classified catalog. The possibilities of this "easy reclassification," as he terms it, should be investigated by students of the technical processes.

Nonclassification, like nonsubject cataloging, has also been proposed and followed in a number of libraries. Periodicals, newspapers, dissertations, reports, obsolete materials, juvenile collections, textbooks, and documents are among the types of materials which have been either broadly classified or not classified at all.

There are some data regarding the potential usefulness of classification and of the use made of systematic arrangement for locating materials. Kelley has demonstrated that classification meets only one third of the potential needs of serious research workers approaching their material from a subject angle.

In a recent study by the writer of library and catalog use by 594 faculty members in two universities, it was found that only about one fourth of the 288 who responded directly used the stacks with any significant frequency. Approximately three fourths of the total number of faculty members responding use the card catalogs in either the departmental or the general library. This is only a little more than 12 per cent of the total faculties. The use of the catalog in departmental libraries is primarily by faculty members who are seeking the locations of new titles. The general card catalog is used mostly by individuals who are searching for entries of new acquisitions or for titles outside their own departmental interests. Forty-one per cent always consulted the card catalog when looking for specific materials. It was also found that except for the Dewey classification, which is known to practically every one who has used libraries, faculty knowledge of classi- 
fications other than that of the Library of Congress, is dispersed widely among twenty-one systems. This last fact suggests that the librarian select one system, the L.C. or some other, and apply it consistently. Deviations are expensive and their values in user satisfaction are questionable.

\section{Centralization and Cooperation}

Librarians have long paid homage to the idea of centralized and standardized cataloging and classification. The appearance of Library of Congress printed cards, subject heading lists, and classification schedules has been regarded by some librarians to be at least one substantial effort to translate an idea into practice. It is interesting, therefore, to observe the extent to which a group of libraries avail themselves of the classification and cataloging services of the Library of Congress. On the basis of data collected from sixtysix college and university libraries using the Library of Congress classification, it may be shown briefly how closely libraries have accepted L.C. class number assignments, subject headings, and analytical entries for series.

\section{L.C. Class Number Assignments}

In only eleven of sixty libraries are L.C. class number assignments accepted in practically every case. Reasons for deviating include L.C. provision of alternative locations, faculty preferences, existence of departmental library systems and special collections, temporary classification, local library policies in handling series, and individual classifiers' idiosyncrasies. In a few of the larger libraries the practice of borrowing manuscript L.C. schedules in incomplete form has made it necessary to forego the use of current L.C. assignments.
Whatever the reason, the fact remains that a large number of libraries do not or are not able to take full advantage of centralized classification. This is an important point, for it indicates some of the real difficulties of centralized classification.

\section{L.C. Subject Headings}

In seven of sixty-six libraries supplying data, L.C. subject headings have been accepted without modification. In other libraries, subdivisions have been omitted; newer headings substituted, particularly on old L.C. cards; or additional headings supplied. The larger the library, the more likely it is to take advantage of L.C. subject heading work without considerable alteration.

\section{Analysis of Series}

The analysis of series represents considerable cataloging beyond the usual cataloging activities in many libraries. This type of work is assumed by librarians to perform a task not accomplished by classification. Complete utilization of the analytical work of L.C. and the Cooperative Cataloging Committee is found in five of the larger libraries. Since this work is costly, a study of the use of analytics seems to be in order. If, as it has been indicated, humanists and scientists do not require this service, is analytical work too expensive a procedure for the average reader?

\section{Conclusions}

On the basis of the limited facts that we have, at least four points may be made in summary. These may suggest a possible road for the future.

( I) Catalogs in general university libraries probably should become merely finding lists and buying guides. Subject 
catalogs, either in card form or in bibliographies, should be made by subject specialists to fit special needs. These catalogs should be compiled cooperatively after the needs are systematically determined.

(2) Subjective impressions of reference and circulation librarians should be given some consideration in determining cataloging policies, but they should be critically appraised by administrators and catalogers. Too many policies of an encyclopedic, bibliographical, or biographical nature have been introduced because of occasional or supposedly potential demands.
(3) Classification is primarily a librarian's device. As such, the acceptance of one system, preferably one based on a living collection of books, seems the effective procedure for the future. Both period cataloging and period classification should be systematically experimented with for selection of the preferred form.

(4) We cannot expect the program of cooperative and centralized cataloging and classification to be any more than empty words unless catalogers stop thinking of all sorts of reasons for not taking advantage of it.

By DAVID J. HAYKIN

\section{Way to the Future: Cooperative and Centralized Cataloging}

\author{
Mr. Haykin is chief, Subject Cataloging \\ Division, Library of Congress.
}

The terms cooperative cataloging and centralized cataloging appear to be perfectly clear and unambiguous. An examination of the literature, however, shows that they have a respectably long semantic history. To begin with, the term "cataloging" itself did not always have the connotation now current in library literature. Until the last three or four decades, it meant, among other things, the preparation of lists of books on different subjects and of different kinds, as well as of socalled universal catalogs, such as that of the International Institute of Bibliography in Brussels. In that sense it is, of course, synonymous with one of the present mean- ings of the word "bibliography." An examination of the Bibliography of Cooperative Cataloguing by Torstein Jahr and Adam J. Strohm offers unmistakable evidence on this point. A polemic engaged in as recently as the early I930's by the then chairman of the A.L.A. Committee on Bibliography, Ernest Cushing Richardson, and officers of the Association on the scope of the work of that committee as against that of the Committee on Cataloging, is further and more recent evidence on this point. For the purpose of the present discussion, the term "catalog" will be used in its current, very restricted sense of a list of the books in a given collection or library, or in several such libraries, without reference to limitations of subject or kind of book. 